Research Article

\title{
Synthesis and Application in Anticounterfeiting of RGB Upconversion Nanoparticles
}

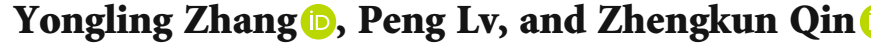 \\ College of Information \& Technology, Jilin Normal University, Siping 136000, China \\ Correspondence should be addressed to Yongling Zhang; yong1ling@163.com and Zhengkun Qin; qin_zhengkun@126.com
}

Received 18 August 2019; Accepted 30 November 2019; Published 20 December 2019

Academic Editor: Domenico Acierno

Copyright (c) 2019 Yongling Zhang et al. This is an open access article distributed under the Creative Commons Attribution License, which permits unrestricted use, distribution, and reproduction in any medium, provided the original work is properly cited.

\begin{abstract}
In this paper, we synthesized $\sim 105 \pm 15 \mathrm{~nm}$ cubic phase $\mathrm{KMnF}_{3}: \mathrm{Yb}^{3+}, \mathrm{Er}^{3+} \mathrm{NPs}, \sim 195 \pm 10 \mathrm{~nm}$ hexagonal phase $\mathrm{NaYF}_{4}: \mathrm{Yb}^{3+}, \mathrm{Tm}^{3+}$ $\mathrm{NPs}$, and $\sim 200 \pm 10 \mathrm{~nm}$ hexagonal phase $\mathrm{NaYF}_{4}: \mathrm{Yb}^{3+}, \mathrm{Er}^{3+} \mathrm{NPs}$. Under the excitation of $980 \mathrm{~nm}$, the strong red upconversion luminescence $\left({ }^{4} \mathrm{~F}_{9 / 2} \longrightarrow{ }^{4} \mathrm{I}_{15 / 2}\right.$, the peak is located at $\left.\sim 653 \mathrm{~nm}\right)$ of $\mathrm{Er}^{3+}$ ions of $\mathrm{KMnF}_{3}: \mathrm{Yb}^{3+}, \mathrm{Er}^{3+} \mathrm{NPs}^{3}$ can be seen, the strong blue upconversion luminescence $\left({ }^{1} \mathrm{D}_{2} \longrightarrow{ }^{3} \mathrm{~F}_{4},{ }^{1} \mathrm{G}_{4} \longrightarrow{ }^{3} \mathrm{H}_{6}\right.$; the peaks are located at $\sim 451 \mathrm{~nm}$ and $\sim 477 \mathrm{~nm}$, respectively) of Tm ${ }^{3+}$ ions of $\mathrm{NaYF}_{4}: \mathrm{Yb}^{3+}, \mathrm{Tm}^{3+} \mathrm{NPs}$ can be observed, and the strong green upconversion luminescence $\left({ }^{4} \mathrm{I}_{11 / 2} \longrightarrow{ }^{4} \mathrm{I}_{15 / 2},{ }^{4} \mathrm{~S}_{3 / 2} \longrightarrow{ }^{4} \mathrm{I}_{15 / 2}\right.$; the peaks are located at $\sim 524 \mathrm{~nm}$ and $\sim 541 \mathrm{~nm}$, respectively) of $\mathrm{Er}^{3+}$ ions of $\mathrm{NaYF}_{4}: \mathrm{Yb}^{3+}, \mathrm{Er}^{3+} \mathrm{NPs}$ can be found. The mixed white upconversion luminescent materials can be obtained by adjusting the doping ratio of the above NPs. Cyclohexane solution of red, blue, green, and the mixed white NPs can be used as ink, and "JLNU" is written on paper with a pen. Without $980 \mathrm{~nm}$ radiation, nothing could be seen. Under $980 \mathrm{~nm}$ irradiation, the colored letters "JLNU" can be seen. Red, blue, green, and the mixed white upconversion NPs can be used in security anticounterfeiting.
\end{abstract}

\section{Introduction}

Lanthanide-doped nanoparticles (NPs) have been widely used in many fields due to sharp emission peaks, stable chemical properties, and a long fluorescence lifetime, such as optical waveguide amplifiers, biomarkers, bioimaging, and three-dimensional display [1-7]. In recent years, lanthanide-doped NPs have shown great application prospects in anticounterfeiting applications [8-10]. Li et al. [11] synthesized $\mathrm{NaGdF}_{4}: \mathrm{Yb}, \mathrm{Er}_{0} @ \mathrm{NaYF}_{4}: \mathrm{Yb} @ N a G d F_{4}: \mathrm{Yb}, \mathrm{Nd} @-$ $\mathrm{NaYF}_{4} @ \mathrm{NaGdF}_{4}: \mathrm{Yb}, \mathrm{Tm} @ \mathrm{NaYF}_{4} \mathrm{NPs}$ by high temperature thermal decomposition. Excited at $980 \mathrm{~nm}$, the prepared NPs show ultraviolet and blue upconversion luminescence coming from $\mathrm{Tm}^{3+}$ ions. Under the excitation of $796 \mathrm{~nm}$, the prepared NPs show green and red upconversion luminescence coming from $\mathrm{Er}^{3+}$ ions. The multishell NPs can be applied to dual anticounterfeiting security design. Lei et al. [12] prepared $\mathrm{Na}_{3} \mathrm{ZrF}_{7}: \mathrm{Yb}, \mathrm{Er} \mathrm{NPs}$ and $\mathrm{Na}_{3} \mathrm{Zr}$ $\mathrm{F}_{7}: \mathrm{Yb}, \mathrm{Ho}$ NPs. Under the excitation of $980 \mathrm{~nm}$, these NPs can display upconversion luminescence of $\mathrm{Er}^{3+}$ and $\mathrm{Ho}^{3+}$ ions, which can be applied to security anticounter- feiting. Han et al. [13] fabricated $\mathrm{NaYF}_{4}: 2 \% \mathrm{Er}, 0.5 \% \mathrm{Tm} @$ $\mathrm{NaYF}_{4}$ core-shell NPs, and the prepared NPs show different fluorescent colors by controlling the pulse duration and repetition frequency of the pump light. This optical property of $\mathrm{NaYF}_{4}: 2 \% \mathrm{Er}, 0.5 \% \mathrm{Tm} @ \mathrm{NaYF}_{4}$ core-shell NPs can be applied to antifake printing. Based on the application of lanthanide-doped NPs in anticounterfeiting, we have done the following research work. In our work, cubic $\mathrm{KMnF}_{3}: 18 \% \mathrm{Yb}^{3+}, 1 \% \mathrm{Er}^{3+} \mathrm{NPs}$, hexagonal $\mathrm{NaYF}_{4}: 18 \% \mathrm{Yb}^{3+}, 0.5 \% \mathrm{Tm}^{3+} \mathrm{NPs}$, and hexagonal $\mathrm{NaYF}_{4}: 18 \% \mathrm{Yb}^{3+}, 2 \% \mathrm{Er}^{3+} \mathrm{NPs}$ with oleic acid functional groups on the surface were successfully fabricated. We characterize the crystalline phases (XRD) and morphologies (SEM) of the three NPs. Meanwhile, we also monitored the fluorescence spectra of the three NPs under $980 \mathrm{~nm}$ excitation. Interestingly, we obtained the mixed white NPs by adjusting the doping ratio of the three NPs. The fluorescence spectra of white NPs stimulated by $980 \mathrm{~nm}$ can be obtained. These four NPs, which emit upconversion luminescence of red, blue, green, and mixed white, can be applied to anticounterfeiting. 


\section{Experimental}

2.1. Preparation of Red, Blue, and Green Nanoparticles. The preparation process of red upconversion $\mathrm{KMnF}_{3}: \mathrm{Yb}^{3+}, \mathrm{Er}^{3+}$ NPs is shown as follows: oleic acid, ethanol, and deionized water were poured into $50 \mathrm{ml}$ beakers as reaction solvents with volumes of $10 \mathrm{ml}, 5 \mathrm{ml}$, and $5 \mathrm{ml}$, respectively. $12 \mathrm{mmol}$ $\mathrm{KOH}$ was poured into the aforementioned beaker, and the reaction solution was stirred for half an hour. Next, $\mathrm{YbCl}_{3} \cdot 6 \mathrm{H}_{2} \mathrm{O}, \mathrm{ErCl}_{3} \cdot 6 \mathrm{H}_{2} \mathrm{O}$, and $\mathrm{MnCl}_{2}$ with moles of $0.072 \mathrm{mmol}, 0.008 \mathrm{mmol}$, and $0.32 \mathrm{mmol}$, respectively, were poured into the aforementioned beaker in sequence. Then, the reaction solution was stirred for another half an hour. $3.5 \mathrm{mmol} \mathrm{KF}$ was poured into the aforementioned beaker under stirring conditions. Finally, all the solutions in the beaker were placed in the hydrothermal reactor and kept at 200 degrees for 12 hours. The reaction product was centrifugally washed with a mixture of ethanol and cyclohexane $[14,15]$.

The preparation process of blue upconversion $\mathrm{NaYF}_{4}$ : $\mathrm{Yb}^{3+}, \mathrm{Tm}^{3+} \mathrm{NPs}$ and green upconversion $\mathrm{NaYF}_{4}: \mathrm{Yb}^{3+}, \mathrm{Er}^{3+}$ NPs is the same. The specific preparation process is shown below: $4 \mathrm{ml}$ oleic acid, $6 \mathrm{ml}$ octadecene, and $0.4 \mathrm{mmol}$ $\mathrm{ReCl}_{3} \cdot 6 \mathrm{H}_{2} \mathrm{O}$ were poured into a $50 \mathrm{ml}$ two-necked flask with round bottom and kept at 150 degrees for an hour with stirring. Argon needed to be introduced into the reaction system. After the reaction solution was cooled, $8 \mathrm{ml}$ methanol solution containing $1 \mathrm{mmol} \mathrm{NaOH}$ and $1.2 \mathrm{mmol} \mathrm{NH}_{4} \mathrm{~F}$ was poured into the aforementioned round bottom. The reaction system was stirred for half an hour. And the temperature of the reaction solution was raised to 50 degrees with stirring. In this process, argon was needed to flow into the atmosphere. Finally, the reaction solution was heated to 300 degrees and kept an hour with stirring. Argon was needed to flow into the atmosphere. The reaction product was centrifugally washed with a mixture of ethanol and cyclohexane [16, 17].

2.2. Characterizations. The X-ray powder diffraction (XRD) of red, blue, and green NPs was achieved via Rigaku RU200B $\left(\lambda=1.5406 \AA\right.$, scanning range: $\left.10^{\circ}-70^{\circ}\right)$. The scanning electron microscope (SEM) of red, blue, and green NPs was obtained through JSM-7500F, JEOL, Japan. All upconversion spectra in this paper were collected via the Hitachi F-4500 fluorescence spectrophotometer. All color photographs of this paper were taken by Nikon D3200.

\section{Results and Discussion}

The solvothermal strategy was used to synthesize $\mathrm{KMnF}_{3}: 18 \% \mathrm{Yb}^{3+}, 1 \% \mathrm{Er}^{3+} \mathrm{NPs}$, and the detailed synthesis steps of $\mathrm{KMnF}_{3}: \mathrm{Yb}^{3+}{ }^{3+} \mathrm{Er}^{3+} \mathrm{NPs}$ have been given in the experimental part (Section 2.1). Figure 1 displayed the XRD and $\mathrm{SEM}$ of $\mathrm{KMnF}_{3}: \mathrm{Yb}^{3+}, \mathrm{Er}^{3+} \mathrm{NPs}$. From the analysis of the results, synthetic $\mathrm{KMnF}_{3}: \mathrm{Yb}^{3+}, \mathrm{Er}^{3+} \mathrm{NPs}$ are cubic $\mathrm{KMnF}_{3}$ crystals, because all diffraction peaks of synthetic $\mathrm{KMnF}_{3}: \mathrm{Yb}^{3+}, \mathrm{Er}^{3+} \mathrm{NPs}$ and the cubic $\mathrm{KMnF}_{3}$ standard card (JCPDS: 82-1334) are in the same position (Figure 1(a)). The synthetic $\mathrm{KMnF}_{3}: \mathrm{Yb}^{3+}, \mathrm{Er}^{3+} \mathrm{NPs}$ could be assigned a cubic structure, and its size is $\sim 105 \pm 15 \mathrm{~nm}$ (Figure 1(b)).
The high temperature thermal decomposition strategy was adopted to prepare $\mathrm{NaYF}_{4}: 18 \% \mathrm{Yb}^{3+}, 0.5 \% \mathrm{Tm}^{3+} \mathrm{NPs}$, and the operation steps of the experiment were introduced in the experimental part (Section 2.1). Figure 2 exhibits the XRD and SEM of $\mathrm{NaYF}_{4}: \mathrm{Yb}^{3+}, \mathrm{Tm}^{3+} \mathrm{NPs}$. As can be seen from Figure 2(a), the prepared $\mathrm{NaYF}_{4}: \mathrm{Yb}^{3+}, \mathrm{Tm}^{3+} \mathrm{NPs}$ could be assigned a hexagonal structure. That is because the positions of all diffraction peaks of $\mathrm{NaYF}_{4}: \mathrm{Yb}^{3+}, \mathrm{Tm}^{3+} \mathrm{NPs}$ and the hexagonal $\mathrm{NaYF}_{4}$ standard card (JCPDS: 28-1192) are identical. Besides, the morphology of $\mathrm{NaYF}_{4}: \mathrm{Yb}^{3+}, \mathrm{Tm}^{3+}$ NPs is hexagonal, and its size is $\sim 195 \pm 10 \mathrm{~nm}$ (Figure 2(b)). The synthesis process of $\mathrm{NaYF}_{4}: 18 \% \mathrm{Yb}^{3+}, 2 \% \mathrm{Er}^{3+} \mathrm{NPs}$ is the same as that of $\mathrm{NaYF}_{4}: \mathrm{Yb}^{3+}, \mathrm{Tm}^{3+} \mathrm{NPs}$. Figure 3 shows the $\mathrm{XRD}$ and $\mathrm{SEM}$ of $\mathrm{NaYF}_{4}: 18 \% \mathrm{Yb}^{3+}, 2 \% \mathrm{Er}^{3+} \mathrm{NPs}$. It has been found from Figure 3(a) that the position of the diffraction peak of $\mathrm{NaYF}_{4}: \mathrm{Yb}^{3+}, \mathrm{Er}^{3+} \mathrm{NPs}$ is exactly the same as that of the hexagonal $\mathrm{NaYF}_{4}$ standard card (JCPDS: 28-1192), hereby certifying that the prepared $\mathrm{NaYF}_{4}: \mathrm{Yb}^{3+}, \mathrm{Er}^{3+} \mathrm{NPs}$ could be assigned a hexagonal structure. Another conclusion can be drawn from Figure 3(b) that $\mathrm{NaYF}_{4}: \mathrm{Yb}^{3+}, \mathrm{Er}^{3+}$ NPs are $\sim 200 \pm 10 \mathrm{~nm}$.

Upconversion fluorescence spectra of $\mathrm{KMnF}_{3}: 18 \% \mathrm{Yb}^{3+}$, $1 \% \mathrm{Er}^{3+} \mathrm{NPs}, \mathrm{NaYF}_{4}: 18 \% \mathrm{Yb}^{3+}, 0.5 \% \mathrm{Tm}^{3+} \mathrm{NPs}$, and $\mathrm{NaYF}_{4}$ : $18 \% \mathrm{Yb}^{3+}, 2 \% \mathrm{Er}^{3+} \mathrm{NPs}$ excited by $980 \mathrm{~nm}$ are shown in Figures 4(a)-4(c). The fluorescence photographs of the corresponding NP cyclohexane solution are embedded in each figure. Figure 4(d) displays the CIE color coordinates of the corresponding NPs excited by $980 \mathrm{~nm}$. In the fluorescence spectra of $\mathrm{KMnF}_{3}: 18 \% \mathrm{Yb}^{3+}, 1 \% \mathrm{Er}^{3+} \mathrm{NPs}$, an emission peak at $\sim 653 \mathrm{~nm}$ can be clearly seen as a result of ${ }^{4} \mathrm{~F}_{9 / 2} \longrightarrow{ }^{4} \mathrm{I}_{15 / 2}$ radiation transition, which is due to the existence of efficient energy transfer between $\mathrm{Er}^{3+}$ and $\mathrm{Mn}^{2+}:{ }^{2} \mathrm{H}_{11 / 2},{ }^{4} \mathrm{~S}_{3 / 2}$ $+{ }^{6} \mathrm{~A}_{1} \longrightarrow{ }^{4} \mathrm{I}_{15 / 2}+{ }^{4} \mathrm{~T}_{1}, \quad{ }^{2} \mathrm{H}_{9 / 2}+{ }^{6} \mathrm{~A}_{1} \longrightarrow{ }^{4} \mathrm{I}_{13 / 2}+{ }^{4} \mathrm{~T}_{1}$, and $\quad{ }^{4} \mathrm{I}_{15 / 2}$ $+{ }^{4} \mathrm{~T}_{1} \longrightarrow{ }^{4} \mathrm{~F}_{9 / 2}+{ }^{6} \mathrm{~A}_{1}[14,15]$ (the energy-level diagram of $\mathrm{KMnF}_{3}: \mathrm{Yb}^{3+}, \mathrm{Er}^{3+} \mathrm{NPs}$ excited with a $980 \mathrm{~nm}$ laser is shown in Figure S1). Therefore, $\mathrm{KMnF}_{3}: \mathrm{Yb}^{3+}, \mathrm{Er}^{3+} \mathrm{NPs}$ can emit red fluorescence, which can be demonstrated by digital photos and the CIE color coordinates of $\mathrm{KMnF}_{3}: \mathrm{Yb}^{3+}, \mathrm{Er}^{3+}$ NPs. From Figure 4(b), it appears that $\mathrm{NaYF}_{4}: \mathrm{Yb}^{3+}, \mathrm{Tm}^{3+}$ NPs have three emission peaks: a strong emission peak at $477 \mathrm{~nm}\left({ }^{1} \mathrm{G}_{4} \longrightarrow{ }^{3} \mathrm{H}_{6}\right)$ and two weak emission peaks at $451 \mathrm{~nm}\left({ }^{1} \mathrm{D}_{2} \longrightarrow{ }^{3} \mathrm{~F}_{4}\right)$ and $644 \mathrm{~nm}\left({ }^{3} \mathrm{~F}_{3} \longrightarrow{ }^{3} \mathrm{H}_{6}\right)$. All emission peaks come from radiation transition of $\mathrm{Tm}^{3+}$ ions in $\mathrm{NaYF}_{4}: \mathrm{Yb}^{3+}, \mathrm{Tm}^{3+} \mathrm{NPs}$ (the energy-level diagram of $\mathrm{NaYF}_{4}: \mathrm{Yb}^{3+}, \mathrm{Tm}^{3+} \mathrm{NPs}$ excited with a $980 \mathrm{~nm}$ laser is shown in Figure S2). Compared with the fluorescence emission intensity at $477 \mathrm{~nm}$, the emission at 451 and $644 \mathrm{~nm}$ can be neglected, so $\mathrm{NaYF}_{4}: \mathrm{Yb}^{3+}, \mathrm{Tm}^{3+} \mathrm{NPs}$ show blue fluorescence emission, which can be seen from the photographs and the CIE color coordinates of $\mathrm{NaYF}_{4}: \mathrm{Yb}^{3+}, \mathrm{Tm}^{3+} \mathrm{NPs}$. As you can see in Figure 4(c), in the fluorescence spectra of $\mathrm{NaYF}_{4}: \mathrm{Yb}^{3+}, \mathrm{Er}^{3+} \mathrm{NPs}$, a strong green upconversion emission peak $(\sim 541 \mathrm{~nm})$ can be seen, which is attributed to the energy-level transition process of ${ }^{4} \mathrm{~S}_{3 / 2} \longrightarrow{ }^{4} \mathrm{I}_{15 / 2}$. Three weak upconversion emission peaks $(\sim 524 \mathrm{~nm}, \sim 410 \mathrm{~nm}$, and $\sim 657 \mathrm{~nm})$ can be seen, which are attributed to the energy-level transition process of ${ }^{4} \mathrm{I}_{11 / 2} \longrightarrow{ }^{4} \mathrm{I}_{15 / 2}, \quad{ }^{2} \mathrm{H}_{9 / 2} \longrightarrow{ }^{4} \mathrm{I}_{15 / 2}$, and ${ }^{4} \mathrm{~F}_{9 / 2} \longrightarrow{ }^{4} \mathrm{I}_{15 / 2} \quad$ (the energy-level diagram of $\mathrm{NaYF}_{4}: \mathrm{Yb}^{3+}, \mathrm{Er}^{3+} \mathrm{NPs}$ excited with 


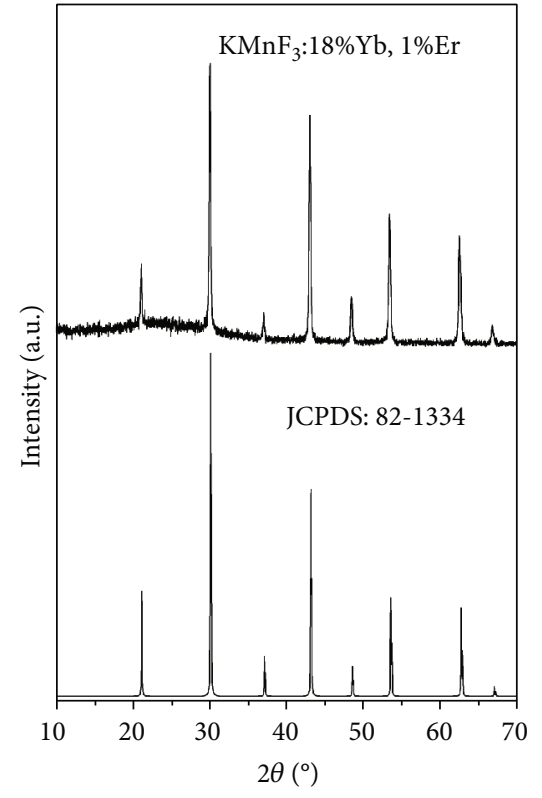

(a)

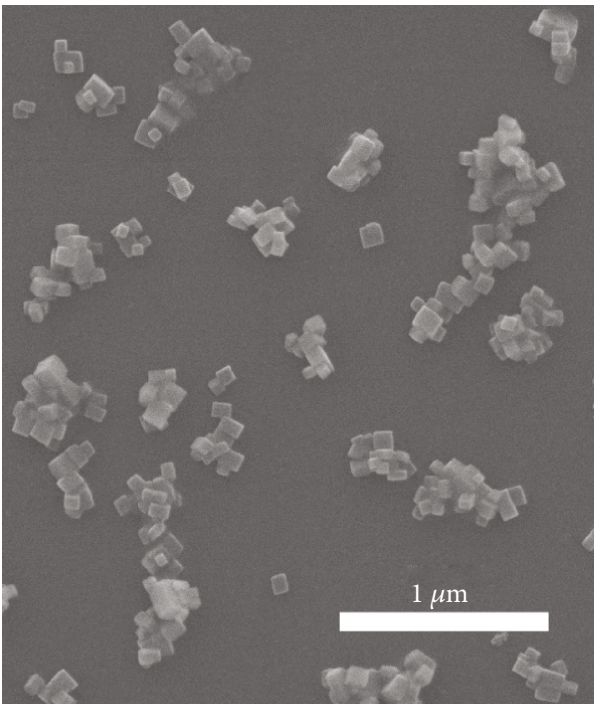

(b)

Figure 1: (a) The XRD of $\mathrm{KMnF}_{3}: \mathrm{Yb}^{3+}, \mathrm{Er}^{3+} \mathrm{NPs}$ and a standard card (JCPDS: 82-1334). (b) The SEM image of $\mathrm{KMnF}_{3}: \mathrm{Yb}^{3+}, \mathrm{Er}^{3+} \mathrm{NPs}$

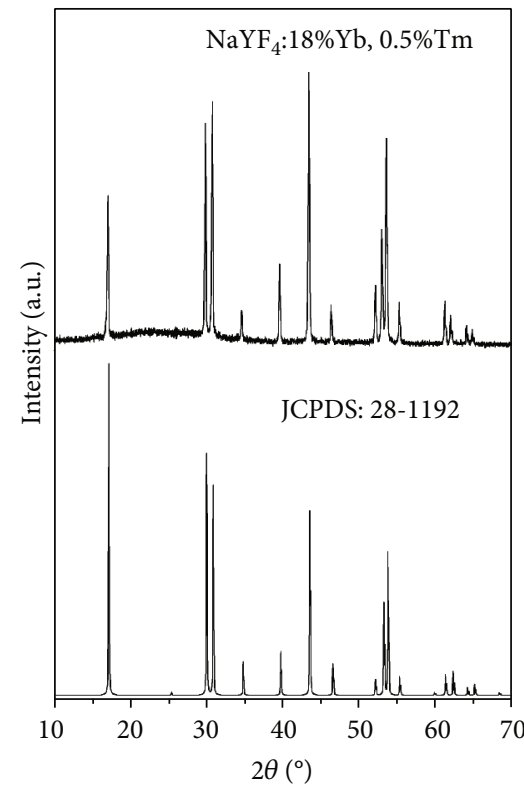

(a)

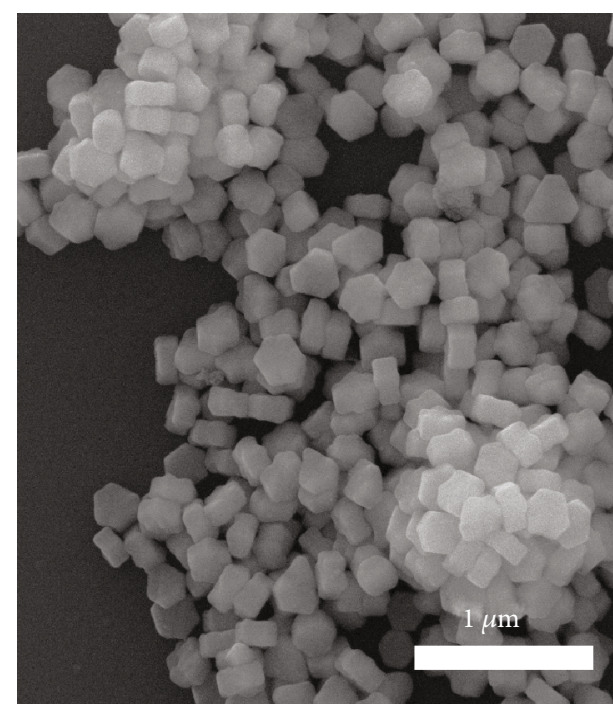

(b)

Figure 2: (a) The XRD of $\mathrm{NaYF}_{4}: \mathrm{Yb}^{3+}, \mathrm{Tm}^{3+} \mathrm{NPs}$ and a standard card (JCPDS: 28-1192). (b) The SEM image of $\mathrm{NaYF}_{4}: \mathrm{Yb}^{3+}, \mathrm{Tm}^{3+} \mathrm{NPs}$

a $980 \mathrm{~nm}$ laser is shown in Figure S3). Because these three emission peaks are too weak, the fluorescence color of $\mathrm{NaYF}_{4}: \mathrm{Yb}^{3+}, \mathrm{Er}^{3+}$ NPs show a green upconversion fluorescence. It can be proven in the digital photos and the $\mathrm{CIE}$ color coordinates of $\mathrm{NaYF}_{4}: \mathrm{Yb}^{3+}, \mathrm{Er}^{3+} \mathrm{NPs}$.

In the following experiments, we first mixed $\mathrm{KMnF}_{3}: \mathrm{Yb}^{3+}, \mathrm{Er}^{3+} \mathrm{NPs}, \quad \mathrm{NaYF}_{4}: \mathrm{Yb}^{3+}, \mathrm{Tm}^{3+} \mathrm{NPs}$, and $\mathrm{NaYF}_{4}: \mathrm{Yb}^{3+}, \mathrm{Er}^{3+} \mathrm{NPs}$ in the mass ratio of $42: 54: 4$, respectively, and then dissolved the mixed NPs into cyclohexane.
Under $980 \mathrm{~nm}$ irradiation, the mixed NPs can emit white upconversion luminescence; the fluorescence spectra are shown in Figure 5(a). Three distinct emission peaks can be observed in Figure 5(a); comparing with Figure 4, we can see that the first fluorescent emission is from $\mathrm{Tm}^{3+}$ ions of $\mathrm{NaYF}_{4}: \mathrm{Yb}^{3+}, \mathrm{Tm}^{3+} \mathrm{NPs}$ with wavelengths ranging from $446 \mathrm{~nm}$ to $494 \mathrm{~nm}$, the second fluorescent emission comes from $\mathrm{Er}^{3+}$ ions of $\mathrm{NaYF}_{4}: \mathrm{Yb}^{3+}, \mathrm{Er}^{3+} \mathrm{NPs}$ with wavelengths ranging from $515 \mathrm{~nm}$ to $564 \mathrm{~nm}$, and the third fluorescent 


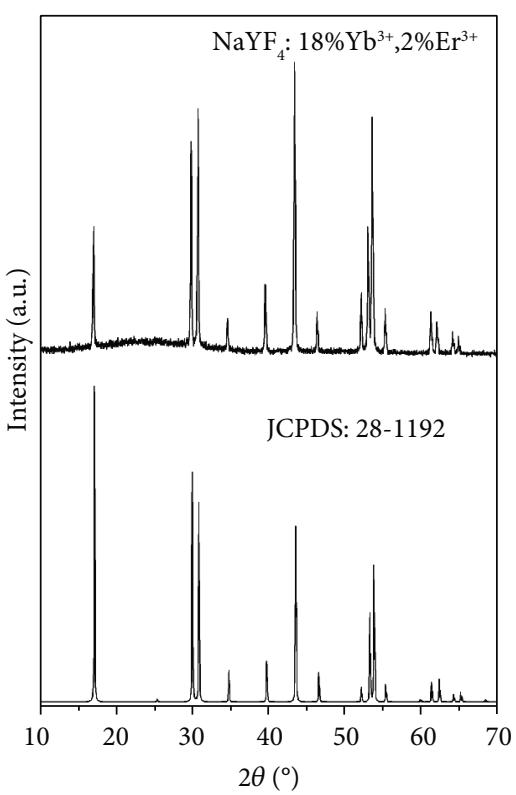

(a)

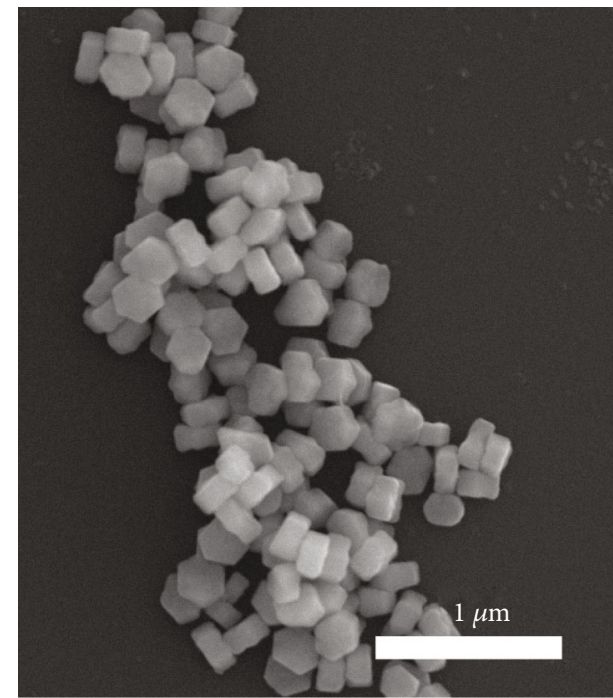

(b)

Figure 3: (a) The XRD of $\mathrm{NaYF}_{4}: \mathrm{Yb}^{3+}, \mathrm{Er}^{3+} \mathrm{NPs}$ and a standard card (JCPDS: 28-1192). (b) The SEM image of $\mathrm{NaYF}_{4}: \mathrm{Yb}^{3+}{ }_{, \mathrm{Er}^{3+}} \mathrm{NPs}$

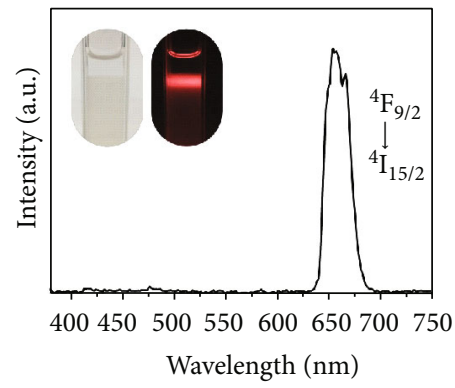

(a)

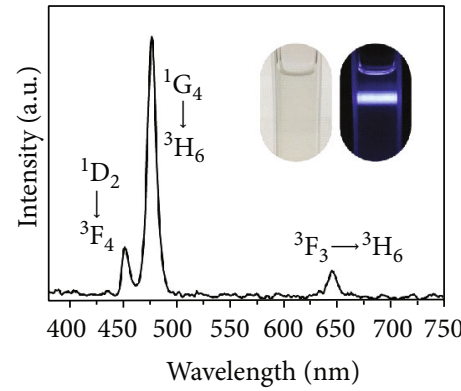

(b)

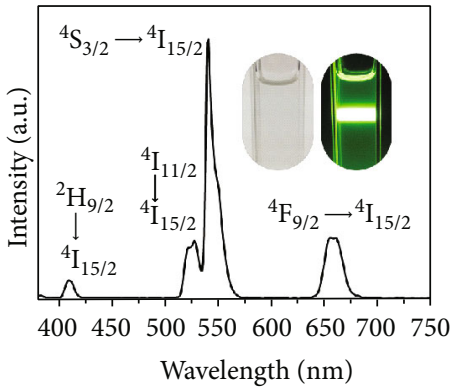

(c)

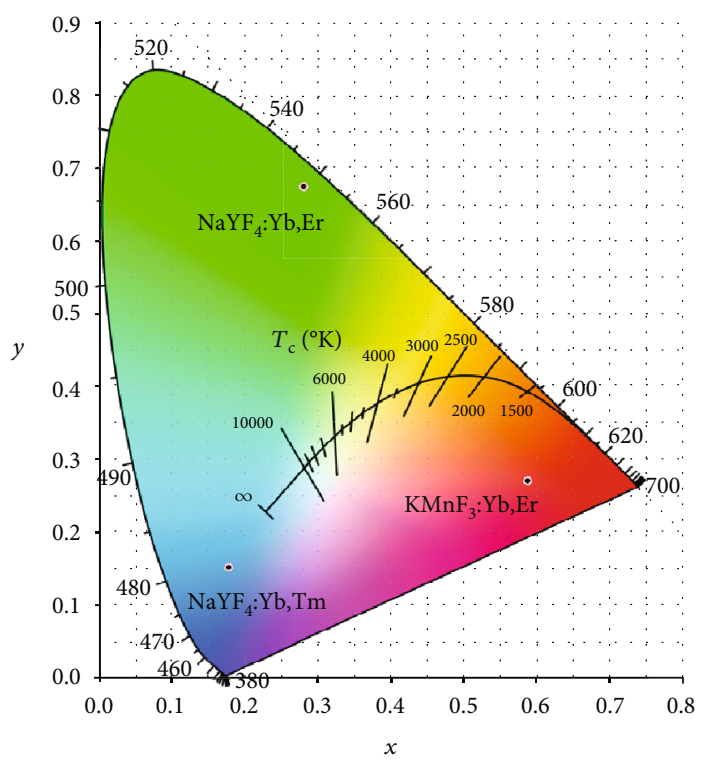

(d)

Figure 4: (a) The upconversion spectrum of (a) $\mathrm{KMnF}_{3}: 18 \% \mathrm{Yb}^{3+}, 1 \% \mathrm{Er}^{3+} \mathrm{NPs}$, (b) $\mathrm{NaYF}_{4}: 18 \% \mathrm{Yb}^{3+}, 0.5 \% \mathrm{Tm}^{3+} \mathrm{NPs}^{3}$ and (c) $\mathrm{NaYF}_{4}: 18 \% \mathrm{Yb}^{3+}, 2 \% \mathrm{Er}^{3+} \mathrm{NPs}$ in $980 \mathrm{~nm}$ excitation. Embedded in every figure is the picture of the corresponding NP cyclohexane solution without or with $980 \mathrm{~nm}$ excitation. (d) The CIE color coordinates of the NPs. 


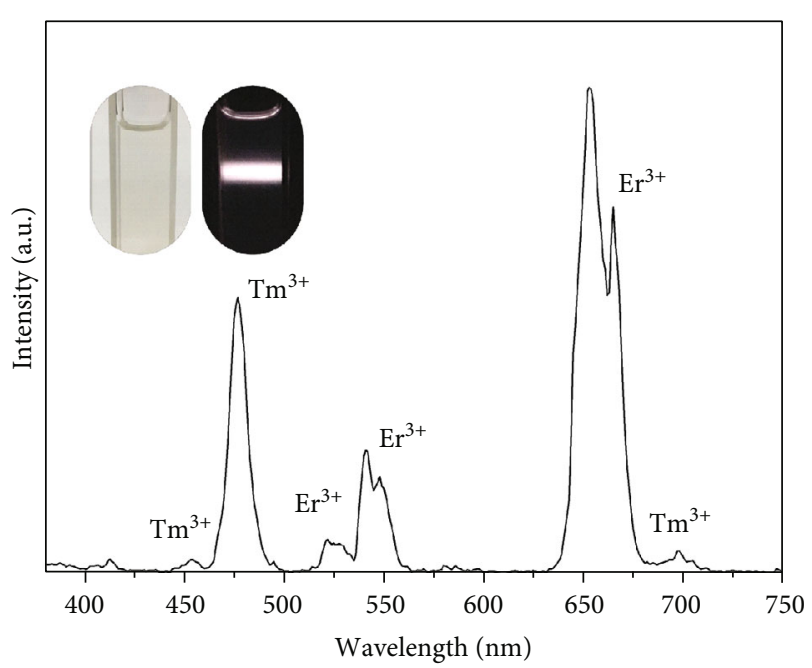

(a)

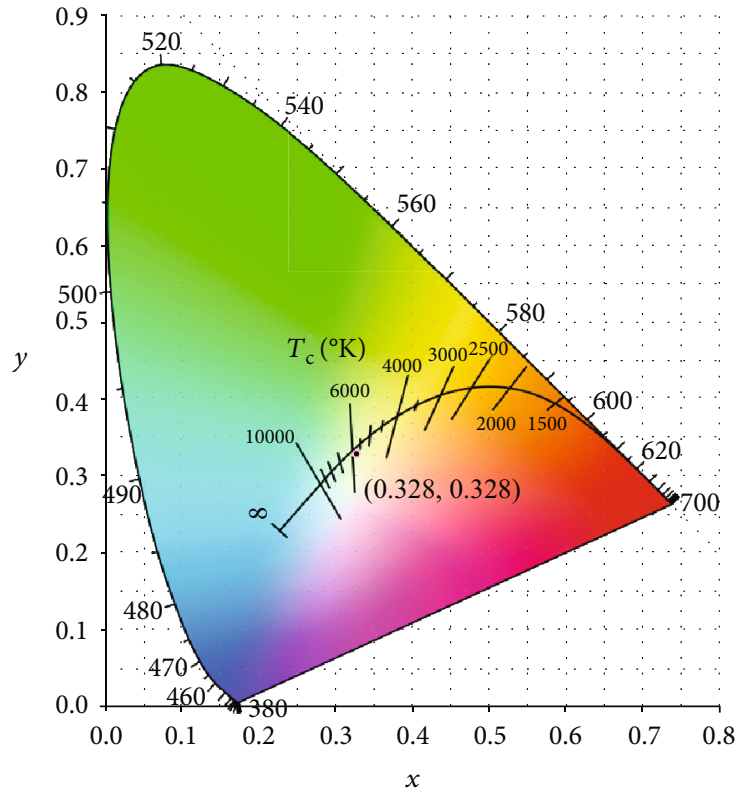

(b)

Figure 5: (a) The upconversion spectrum of the mixed white NPs (mixing of $\mathrm{KMnF}_{3}: \mathrm{Yb}^{3+}, \mathrm{Er}^{3+} \mathrm{NPs} \mathrm{NaYF}_{4}: \mathrm{Yb}^{3+}, \mathrm{Tm}^{3+} \mathrm{NPs}^{3}$ and $\mathrm{NaYF}_{4}: \mathrm{Yb}^{3+}, \mathrm{Er}^{3+} \mathrm{NPs}$ with a mass percentage of $42 \%, 54 \%$, and $4 \%$, respectively) in $980 \mathrm{~nm}$ excitation. Embedded in the figure is the picture of white NP cyclohexane solution without or with $980 \mathrm{~nm}$ excitation. (b) The CIE color coordinates of the mixed white NPs.

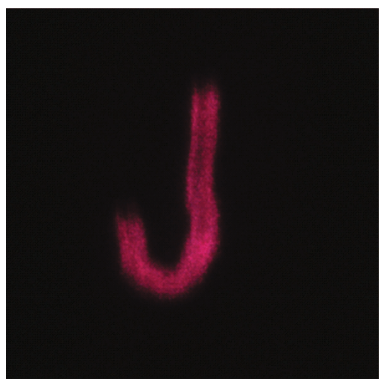

(a)

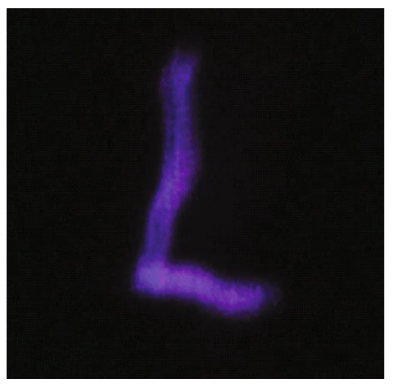

(b)

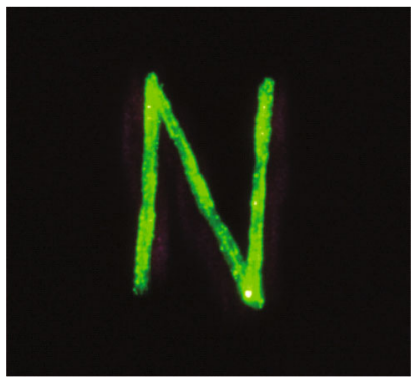

(c)

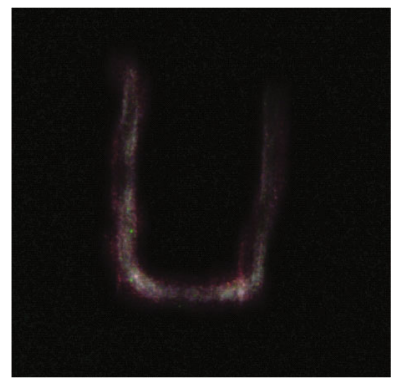

(d)

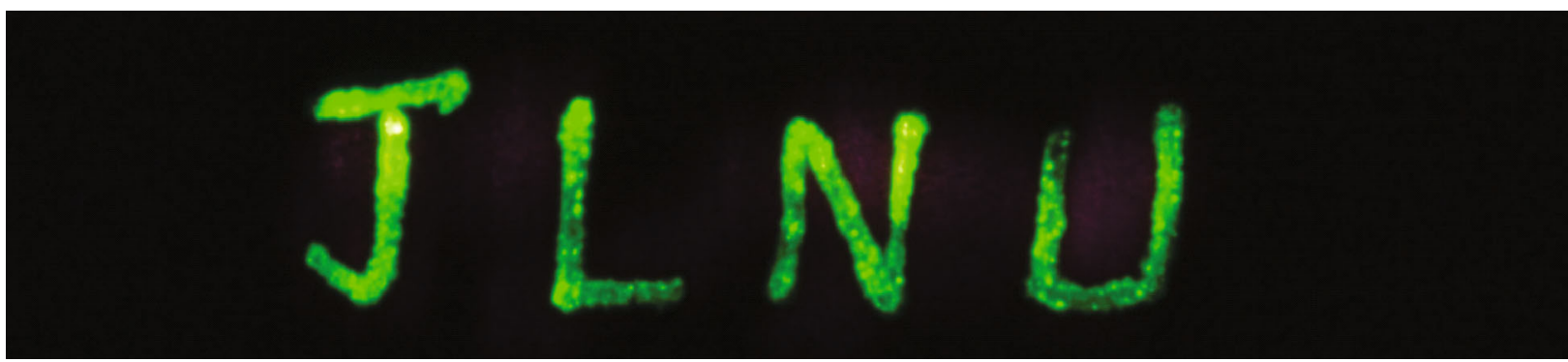

(e)

Figure 6: The anticounterfeiting photographs of (a) $\mathrm{KMnF}_{3}: \mathrm{Yb}^{3+}, \mathrm{Er}^{3+} \mathrm{NPs}$, (b) $\mathrm{NaYF}_{4}: \mathrm{Yb}^{3+}, \mathrm{Tm}^{3+} \mathrm{NPs},(\mathrm{c}) \mathrm{NaYF}_{4}: \mathrm{Yb}^{3+}, \mathrm{Er}^{3+} \mathrm{NPs}^{3+}$ and (d) the mixed white $\mathrm{NPs}$ (mixing of $\mathrm{KMnF}_{3}: \mathrm{Yb}^{3+}{ }^{3+} \mathrm{Er}^{3+} \mathrm{NPs}, \mathrm{NaYF}_{4}: \mathrm{Yb}^{3+}, \mathrm{Tm}^{3+} \mathrm{NPs}$, and $\mathrm{NaYF}_{4}: \mathrm{Yb}^{3+}, \mathrm{Er}^{3+} \mathrm{NPs}$ with a mass percentage of $42 \%$, $54 \%$, and $4 \%$, respectively). (e) $\mathrm{NaYF}_{4}: \mathrm{Yb}^{3+}, \mathrm{Er}^{3+} \mathrm{NPs}$, under $980 \mathrm{~nm}$ irradiation.

emission is from $\mathrm{Er}^{3+}$ ions of $\mathrm{KMnF}_{3}: \mathrm{Yb}^{3+}, \mathrm{Er}^{3+} \mathrm{NPs}$ with wavelengths ranging from $632 \mathrm{~nm}$ to $681 \mathrm{~nm}$. Mixed NPs exhibit white upconversion luminescence, which can be demonstrated by photographs of mixed NPs and the CIE color coordinates of mixed NPs under $980 \mathrm{~nm}$ irradiation.
Interestingly enough, we dissolve red $\mathrm{KMnF}_{3}: \mathrm{Yb}^{3+}, \mathrm{Er}^{3+}$ $\mathrm{NPs}$, blue $\mathrm{NaYF}_{4}: \mathrm{Yb}^{3+}, \mathrm{Tm}^{3+} \mathrm{NPs}$, green $\mathrm{NaYF}_{4}: \mathrm{Yb}^{3+}, \mathrm{Er}^{3+}$ $\mathrm{NPs}$, and the mixed white NPs (mixing of $\mathrm{KMnF}_{3}: \mathrm{Yb}^{3+}, \mathrm{Er}^{3+}$ $\mathrm{NPs}, \mathrm{NaYF}_{4}: \mathrm{Yb}^{3+}, \mathrm{Tm}^{3+} \mathrm{NPs}$, and $\mathrm{NaYF}_{4}: \mathrm{Yb}^{3+}, \mathrm{Er}^{3+} \mathrm{NPs}$ with a mass percentage of $42 \%, 54 \%$, and $4 \%$, respectively) into the 
cyclohexane as ink and write directly on the paper with this ink. Without $980 \mathrm{~nm}$ laser irradiation, no pattern or text can be seen on the paper. Under $980 \mathrm{~nm}$ laser irradiation, four letters of "J," "L," "N," and "U" will appear on the paper, which are written using our own synthetic red, green, blue, and white ink. Under $980 \mathrm{~nm}$ laser excitation, the photographs are shown in Figures 6(a)-6(d). Furthermore, green upconversion NPs were used as ink for writing the letters "JLNU." Under $980 \mathrm{~nm}$ irradiation, we can clearly see the letters "JLNU" appear on paper, as shown in Figure 6(e). Significantly, these four nanoparticles can be used in anticounterfeiting.

\section{Conclusion}

We prepared $\mathrm{KMnF}_{3}: 18 \% \mathrm{Yb}^{3+}, 1 \% \mathrm{Er}^{3+} \quad \mathrm{NPs}, \quad \mathrm{NaYF}_{4}$ : $18 \% \mathrm{Yb}^{3+}, 0.5 \% \mathrm{Tm}^{3+} \mathrm{NPs}$, and $\mathrm{NaYF}_{4}: 18 \% \mathrm{Yb}^{3+}, 2 \% \mathrm{Er}^{3+} \mathrm{NPs}$ encapsulated by oleic acid ligands. Under $980 \mathrm{~nm}$ excitation, $\mathrm{KMnF}_{3}: \mathrm{Yb}^{3+}, \mathrm{Er}^{3+} \mathrm{NPs}$ can emit strong red upconversion luminescence which comes from ${ }^{4} \mathrm{~F}_{9 / 2} \longrightarrow{ }^{4} \mathrm{I}_{15 / 2}$ radiation transition, $\mathrm{NaYF}_{4}: \mathrm{Yb}^{3+}, \mathrm{Tm}^{3+} \mathrm{NPs}$ can send strong blue upconversion emission which comes from ${ }^{1} \mathrm{G}_{4} \longrightarrow{ }^{3} \mathrm{H}_{6}$ radiation transition, and $\mathrm{NaYF}_{4}: \mathrm{Yb}^{3+}, \mathrm{Er}^{3+} \mathrm{NPs}$ can give strong green upconversion emission which comes from ${ }^{4} \mathrm{~S}_{3 / 2} \longrightarrow{ }^{4} \mathrm{I}_{15 / 2}$ radiation transition. Then, the white upconversion NPs can be obtained by mixing the three NPs. These NPs are used as fluorescent anticounterfeiting materials in product safety design.

\section{Data Availability}

All data are obtained through our own experiments. The public database is not used in this article. If the reader needs the data in this article, he can contact the authors (yong1ling@163.com).

\section{Conflicts of Interest}

The authors declare that there is no conflict of interests regarding the publication of this paper.

\section{Acknowledgments}

This work was supported by (1) the Science and Technology Development Plan Project of Jilin Province of China (No. 1: 20180520199JH, No. 2: 20180520191JH), (2) the Science and Technology Project of the Jilin Provincial Education Department of China (No. 1: JJKH20180762KJ, No. 2: JJKH20191006KJ), and (3) the National Natural Science Foundation of China (No. 21701047).

\section{Supplementary Materials}

Figure S1: the energy-level diagram of $\mathrm{KMnF}_{3}: \mathrm{Yb}^{3+}, \mathrm{Er}^{3+}$ NPs excited with a $980 \mathrm{~nm}$ laser. Figure S2: the energylevel diagram of $\mathrm{NaYF}_{4}: \mathrm{Yb}^{3+}, \mathrm{Tm}^{3+} \mathrm{NPs}$ excited with a $980 \mathrm{~nm}$ laser. Figure S3: the energy-level diagram of $\mathrm{NaYF}_{4}: \mathrm{Yb}^{3+}, \mathrm{Er}^{3+}$ NPs excited with a $980 \mathrm{~nm}$ laser. (Supplementary Materials)

\section{References}

[1] X. Zhai, S. Liu, X. Liu et al., "Sub-10 nm BaYF $5: \mathrm{Yb}^{3+}, \mathrm{Er}^{3+}$ core-shell nanoparticles with intense $1.53 \mu \mathrm{m}$ fluorescence for polymer-based waveguide amplifiers," Journal of Materials Chemistry C, vol. 1, no. 7, pp. 1525-1530, 2013.

[2] M. Zhang, W. Zhang, F. Wang et al., "High-gain polymer optical waveguide amplifiers based on core-shell $\mathrm{NaYF}_{4} / \mathrm{NaLuF}_{4}$ : $\mathrm{Yb}^{3+}, \mathrm{Er}^{3+} \mathrm{NPs}-\mathrm{PMMA}$ covalent- linking nanocomposites," Scientific reports, vol. 6, no. 1, article 36729, 2016.

[3] H. Zhang, Y. Fan, P. Pei, C. Sun, L. Lu, and F. Zhang, " $\mathrm{Tm}^{3+}$ sensitized NIR-II fluorescent nanocrystals for in vivo information storage and decoding," Angewandte Chemie, vol. 131, no. 30, pp. 10259-10263, 2019.

[4] P. Zhang, H. Chen, Y. Yang et al., "3D up-conversion display of $\mathrm{NaYF}_{4}$-PMMA covalent-linking nanocomposites," Journal of Alloys and Compounds, vol. 753, pp. 725-730, 2018.

[5] M. Zhao, B. Li, P. Wang et al., "Supramolecularly engineered NIR-II and upconversion nanoparticles in vivo assembly and disassembly to improve bioimaging," Advanced Materials, vol. 30, no. 52, article 1804982, 2018.

[6] T. K. Pathak, A. Kumar, H. C. Swart, and R. E. Kroon, "Effect of annealing on structural and luminescence properties of $\mathrm{Eu}^{3+}$ doped $\mathrm{NaYF}_{4}$ phosphor," Physica B: Condensed Matter, vol. 535, pp. 132-137, 2018.

[7] T. K. Pathak, A. Kumar, L. J. B. Erasmus et al., "Highly efficient infrared to visible up-conversion emission tuning from red to white in $\mathrm{Eu} / \mathrm{Yb}$ co-doped $\mathrm{NaYF}_{4}$ phosphor," Spectrochimica Acta Part A: Molecular and Biomolecular Spectroscopy, vol. 207, pp. 23-30, 2019.

[8] K. Park, M. Park, H. S. Jang et al., "Highly secure plasmonic encryption keys combined with upconversion luminescence nanocrystals," Advanced Functional Materials, vol. 28, no. 21, article 1800369, 2018.

[9] T. Sun, B. Xu, B. Chen et al., "Anti-counterfeiting patterns encrypted with multi-mode luminescent nanotaggants," Nanoscale, vol. 9, no. 8, pp. 2701-2705, 2017.

[10] P. Kumar, J. Dwivedi, and B. K. Gupta, "Highly luminescent dual mode rare-earth nanorod assisted multi-stage excitable security ink for anti-counterfeiting applications," Journal of Materials Chemistry C, vol. 2, no. 48, pp. 10468-10475, 2014.

[11] X. Li, Z. Guo, T. Zhao et al., "Filtration shell mediated power density independent orthogonal excitations-emissions upconversion luminescence," Angewandte Chemie International Edition, vol. 55, no. 7, pp. 2464-2469, 2016.

[12] L. Lei, D. Chen, C. Li, F. Huang, J. Zhang, and S. Xu, "Inverse thermal quenching effect in lanthanide-doped upconversion nanocrystals for anti-counterfeiting," Journal of Materials Chemistry C, vol. 6, no. 20, pp. 5427-5433, 2018.

[13] Y. Han, H. Li, Y. Wang et al., "Upconversion modulation through pulsed laser excitation for anti- counterfeiting," Scientific Reports, vol. 7, no. 1, article 1320, 2017.

[14] Y. Zhang, F. Wang, Y. Lang et al., " $\mathrm{KMnF}_{3}: \mathrm{Yb}^{3+}, \mathrm{Er}^{3+} @-$ $\mathrm{KMnF}_{3}: \mathrm{Yb}^{3+}$ active-core-active-shell nanoparticles with enhanced red up-conversion fluorescence for polymer-based waveguide amplifiers operating at $650 \mathrm{~nm}$," Journal of Materials Chemistry C, vol. 3, no. 38, pp. 9827-9832, 2015.

[15] J. Wang, F. Wang, C. Wang, Z. Liu, and X. Liu, "Single-band upconversion emission in lanthanide-doped $\mathrm{KMnF}_{3}$ nanocrystals," Angewandte Chemie International Edition, vol. 50, no. 44, pp. 10369-10372, 2011. 
[16] F. Wang, R. Deng, and X. Liu, "Preparation of core-shell $\mathrm{NaGdF}_{4}$ nanoparticles doped with luminescent lanthanide ions to be used as upconversion-based probes," Nature Protocols, vol. 9, no. 7, article 1634, 1644 pages, 2014.

[17] Y. Zhang, X. Liu, Y. Lang et al., "Synthesis of ultra-small $\mathrm{BaLuF}_{5}: \mathrm{Yb}^{3+}, \mathrm{Er}^{3+} @ \mathrm{BaLuF}_{5}: \mathrm{Yb}^{3+}$ active-core-active-shell nanoparticles with enhanced up-conversion and down-conversion luminescence by a layer-by-layer strategy," Journal of Materials Chemistry C, vol. 3, no. 9, pp. 2045-2053, 2015. 


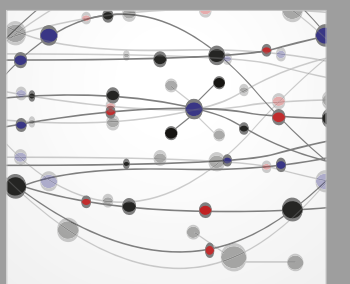

The Scientific World Journal
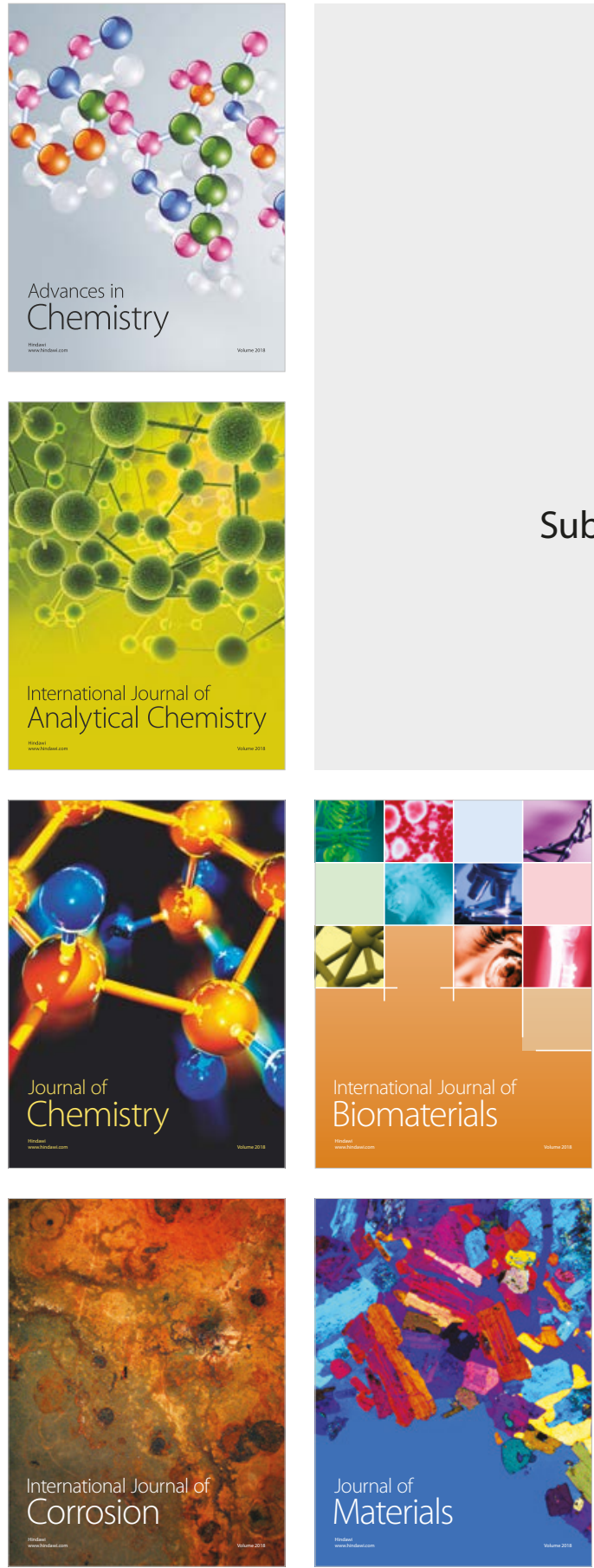

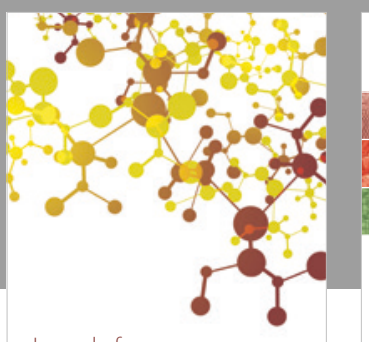

Journal of

Applied Chemistry
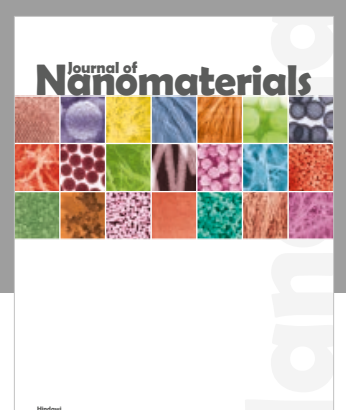

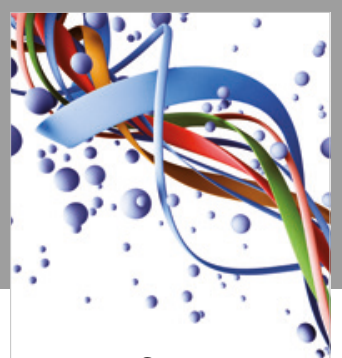

Scientifica

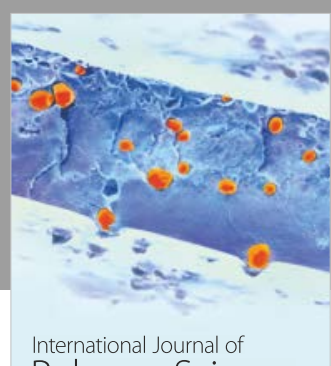

Polymer Science

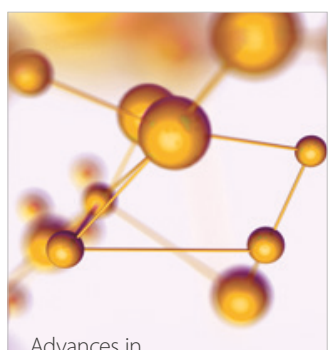

Physical Chemistry
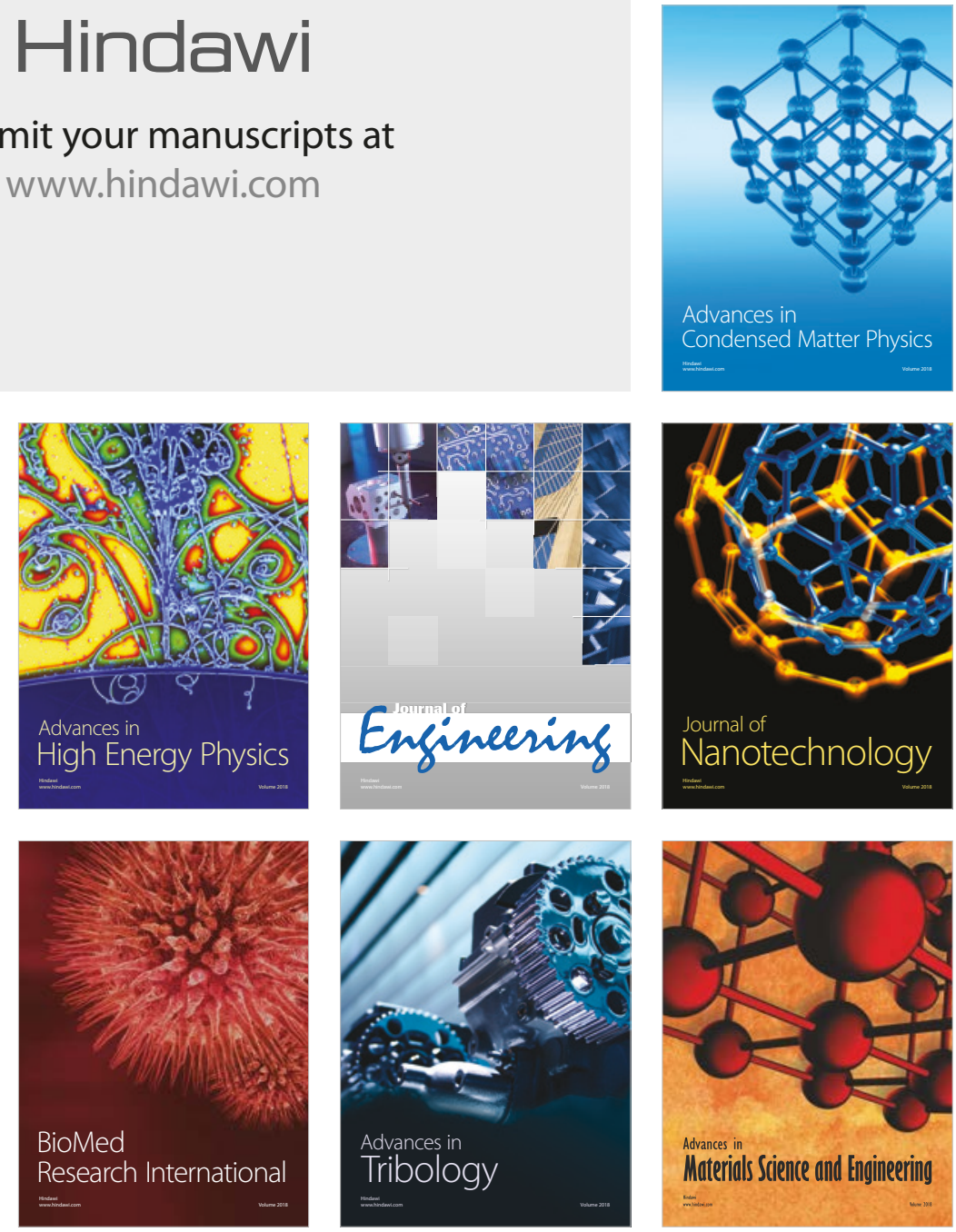